\title{
PROTOTIPAÇÃo E TESTE DE UM PRODUTO DIGITAL DO RAMO FUTEBOLÍSTICO
}

Paulo Francisco Gomes Ferreira (paulo.francisco@acad.pucrs.br) - Pontifícia Universidade Católica do Rio Grande do Sul, PUCRS.

Patrícia Flores Magnago (patricia.magnago@pucrs.br) - Pontifícia Universidade Católica do Rio Grande do Sul, PUCRS.

Álvaro Gehlen De Leão (gehleao@pucrs.br) - Pontifícia Universidade Católica do Rio Grande do Sul, PUCRS.

\section{RESUMO}

A captação e seleção de atletas representa a grande oportunidade dos jovens jogadores de futebol de entrada nos clubes. Porém, percebe-se que este processo ainda tem um alto grau de subjetividade. Este estudo objetiva desenvolver, uma sistemática de seleção alternativa ao processo atual, a partir da análise e coleta de dados mercadológicos e das necessidades dos clientes. Os resultados permitiram prototipar, analisar modos de falhas pelo FMEA e testar em campo a solução gerada. O desenvolvimento do aplicativo englobou soluções para os requisitos dos clientes, como por exemplo: Geração de relatórios com as principais características dos atletas, uma sistemática de filtros que segmentem os atletas de acordo com as necessidades dos clubes e o agrupamento de jogadores por característica. $\mathrm{O}$ aplicativo virtual apresenta aos analistas de futebol relatórios de dados de atletas, colocando as suas características físicas e técnicas, além de vídeos. O protótipo foi mostrado aos usuários, que o avaliaram com uma pesquisa com percepção de $95 \%$ de satisfação sobre e propuseram melhorias para uma segunda rodada de análise.

Palavras chave: protótipo; teste de satisfação; FMEA; aplicativo de futebol; captação de atletas 


\section{INTRODUÇÃO}

O futebol é o esporte mais famoso do mundo e o seu número de adeptos continua crescendo em todo o planeta (NIELSEN COMPANY, 2018). É um esporte que envolve milhões de pessoas apaixonadas pelos clubes e suas histórias e, alguns de seus grandes jogadores são tratados como entidades sagradas pelas suas conquistas. Seu mercado movimenta 53 bilhões na economia brasileira, o que representa $0,72 \%$ do Produto Interno Bruto (PIB) do país (Confederação Brasileira de Futebol - CBF; EY, 2019). Atualmente, o futebol brasileiro conta com 360.291 atletas, entre amadores, profissionais e jogadores cadastrados. Deste todo, 88.000 são profissionais, ou seja, 24,4\%. Dentro deste valor, apenas 11.600 atletas tiveram contratos ativos durante toda a temporada pelos seus clubes, representando 3,2\% do total (CBF; EY, 2019). As chamadas Escolas de Futebol associadas aos grandes clubes realizam as chamadas 'peneiras' para a captação de jovens atletas, e se tornam as principais portas de entrada para acesso a estes clubes (LOPES, 2018). A ideia de criar um aplicativo para a captação de jovens jogadores, para pequenos, médios e grandes clubes de futebol, surgiu pela identificação de uma falha neste nicho específico de mercado.

Para Rosa (2009), os jovens de periferia sonham com a fama e o dinheiro que o futebol traz, mas não têm conhecimento da grande dificuldade que existe no início desta carreira, na qual uma minoria atinge o nível profissional. Caso o atleta não seja selecionado acaba por ter que parar de jogar involuntariamente. Muitos jovens quando param de jogar, acabam em subempregos e à margem da sociedade. Segundo Erthal e Lemos (2010), as escolinhas de futebol são para quem quiser pagar e jogar, porém olheiros e empresários aproveitam entre as levas que se apresentam voluntariamente, para garimpar e fazer dinheiro com adolescentes com disposição para enfrentar desde o início da vida as rotinas de treinos e as disputas por espaço. Complementam que o sonho dos jovens é a carreira dentro das quatro linhas, o objetivo dos empresários é descobrir alguém para formar, valorizar o passe e lucrar.

É de comum acordo entre todos que gostam deste esporte que existem oportunidades a serem levantadas e tratadas, para um direcionamento mais tecnológico e inovador, visando a melhoria do desenvolvimento de processos de clubes e federações. Entre eles, o referido processo de identificação de potenciais novos jogadores. As plataformas online direcionadas para o ambiente futebolístico têm crescido nos últimos anos. A preparação física foi a área mais beneficiada pela ciência e pela tecnologia (MOURA, 1997). Os softwares têm ajudado os analistas de desempenho, fazendo com o que a informação seja retirada rapidamente da análise e sendo assim repassada às comissões técnicas e jogadores (ESTANISLAU, 2016). 
No entanto, são em menor número as soluções de plataformas que visem otimizar a gestão dos clubes com seus atletas (SILVA et al., 2016) - como o caso da captação, seleção e gestão de talentos. Surge assim, a demanda de novas soluções em torno do segmento futebolístico, para facilitar cada vez mais as informações àqueles que planejam ações deste mercado (RUSSO, 2008). Segundo Silbermann (2010) o jogador de futebol transformado em dado informacional descreve estas fronteiras cotidianas pautadas na interação e incorporação progressiva com tecnologia. A partir desta globalização de informações entre os agentes, várias atividades com alto tempo de processamento ainda podem ser reduzidas através da inovação, que pode atuar como facilitador na transformação de clubes e federações.

Neste contexto, este trabalho objetiva responder a seguinte questão da pesquisa. É possível prototipar uma solução inovadora para os jovens jogadores serem vistos pelos clubes através da metodologia do Design Thinking? Para respondê-la, este trabalho tem como objetivo geral propor uma sistemática de captação e seleção de novos talentos do futebol, desenvolvendo uma solução digital para o processo por meio de algumas coletas prévias. Os objetivos específicos são: (i) prototipar a solução resultante das análises; (ii) testar e validar o protótipo com os stakeholders.

O trabalho limita-se em apresentar os resultados da prototipação e teste do produto, e não apresenta os resultados das análises prévias de ideação e imersão no problema, deixando para ser feito em outro trabalho. Limita-se também em realizar a prototipação em telas virtuais, e não propriamente a modulação funcional de um aplicativo, devido às restrições financeiras. A partir da prototipação em telas, os stakeholders têm a possibilidade de ver o molde do aplicativo e argumentar se este atende suas necessidades para uso. Os custos envolvidos com o desenvolvimento de cada componente não foram levantados para este estudo, deixando para serem verificados em outra análise.

\section{REVISÃO TEÓRICA}

\subsection{Prototipação}

A Prototipação é onde acontecem a aplicação da modelagem e conceito do produto. A prototipagem - a disposição de seguir adiante e testar alguma hipótese construindo o objeto é a melhor evidência de experimentação (BROWN; KATZ, 2019). Segundo Brown e Katz (2019), a prototipagem envolve o ato dde "pensar com as mãos" e a compara com o pensamento abstrato orientado por especificações e planejamento.

Os protótipos têm mais sucesso quando pessoas (a equipe de design, usuários e outros) 
podem experimentar e interagir com eles. Eles são uma ótima maneira de começar uma conversa. A prototipagem é muitas vezes considerada uma forma de testar as funcionalidades do produto, mas serve para muitos outros propósitos. Dentre estes propósitos, se considera o aprofundamento da compreensão dos usuários e do espaço de design, o desenvolvimento de vários conceitos para teste, criação de protótipos para testar e refino de soluções (HPID, 2018).

Para a prototipação, o autor desenvolveu uma solução em protótipo virtual não funcional. Utilizou-se a plataforma de design Marvel App para modelar os formatos e componentes não funcionais do aplicativo. Como se trata de um aplicativo que será utilizado em notebooks e celulares, para fins de registro documentado do mesmo, é apresentado em telas, onde suas imagens representam e espelham os resultados das análises previamente realizadas nas etapas anteriores.

É feita uma análise de riscos do protótipo para mitigar potenciais falhas que o produto venha a ter por meio do FMEA. A ferramenta FMEA - Failure Mode and Effect Analysis (Análise de Modo e Efeitos de Falha) é útil no presente trabalho por permitir a análise e detecção de potenciais falhas que o produto venha a ter, identificando soluções para mitigá-las.

\subsection{Teste}

A etapa de teste foi o momento de apresentação do protótipo criado aos clientes e pela busca do feedback. Nesta etapa, é feita uma pesquisa de satisfação com uma amostra dos entrevistados da pesquisa de mercado. Segundo Rossi e Slongo (1998), as informações sobre os níveis de satisfação dos clientes constituem uma das maiores prioridades de gestão nas empresas comprometidas com qualidade de seus produtos e serviços e, por conseguinte, com os resultados alcançados junto a seus clientes.

A etapa de teste permite ao designer criar experiências autênticas para os usuários para testar seus protótipos. Serve também para saber mais sobre o usuário, permitindo construir empatia por meio da observação e engajamento (HPID, 2018). A etapa informa as próximas iterações dos protótipos. Às vezes, isso significa ir de volta à prancheta.

\section{METODOLOGIA}

A aplicação prática do estudo foi realizada conforme as duas últimas etapas do modelo adaptado da HPID (2018), e por meio de algumas ferramentas que conduzem ambas as fases, vide Figura 1, Prototipação e seus riscos pelo FMEA e Teste com feedbacks. 


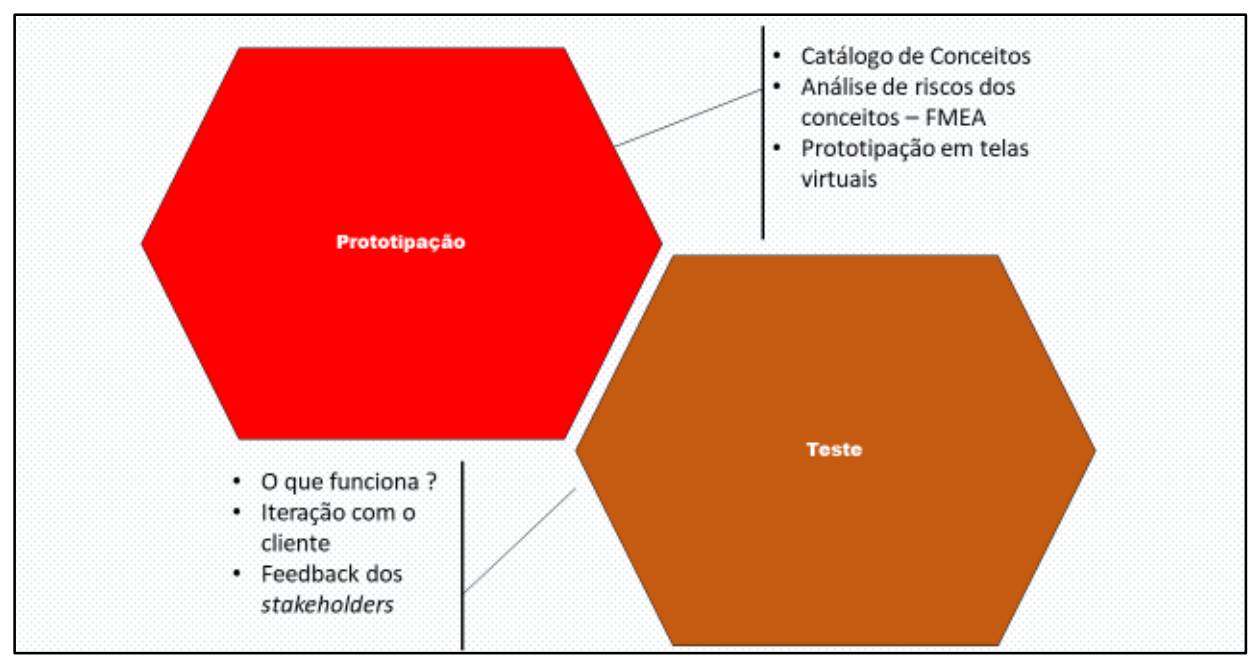

Figura 1 - Processo de Design Thinking. - Fonte: adaptado HPID (2018)

Segundo HPID (2018), a prototipação é constantemente pensada como o caminho para o teste da funcionalidade da solução, visando ganho de empatia com a Persona, exploração das necessidades demandadas, teste das soluções estruturadas e inspiração do designer. Os protótipos obtêm mais sucesso quando todos os stakeholders envolvidos podem experimentar e interagir.

Após a finalização do protótipo e do levantamento das potenciais falhas mapeadas, o aplicativo em telas foi apresentado para oito stakeholders envolvidos na proposta do negócio, com o objetivo de realizar a simulação do mesmo em ambiente virtual e, após isso, avaliar através de uma pesquisa de satisfação. O teste consistiu na aplicação de um questionário para avaliar o aplicativo. O modelo foi apresentado virtualmente na plataforma no qual foi desenvolvida, chamada Marvel App e, em paralelo, elas puderam avaliar no questionário na presença do pesquisador orientador da explicação do protótipo.

\section{RESULTADOS E DISCUSSÃO}

\subsection{Prototipação}

Os requisitos foram colocados nos protótipos no catálogo de conceitos e os planos de ação serviram de base para estruturar a forma dos componentes. Além de planejar e elencar as ações, foram adicionadas imagens, a fim de auxiliar o visual da prototipagem final e para se ter uma ideia de esboço em papel dos componentes do protótipo final. A Figura 2 apresenta os componentes mais importantes do produto desenhados à mão. 


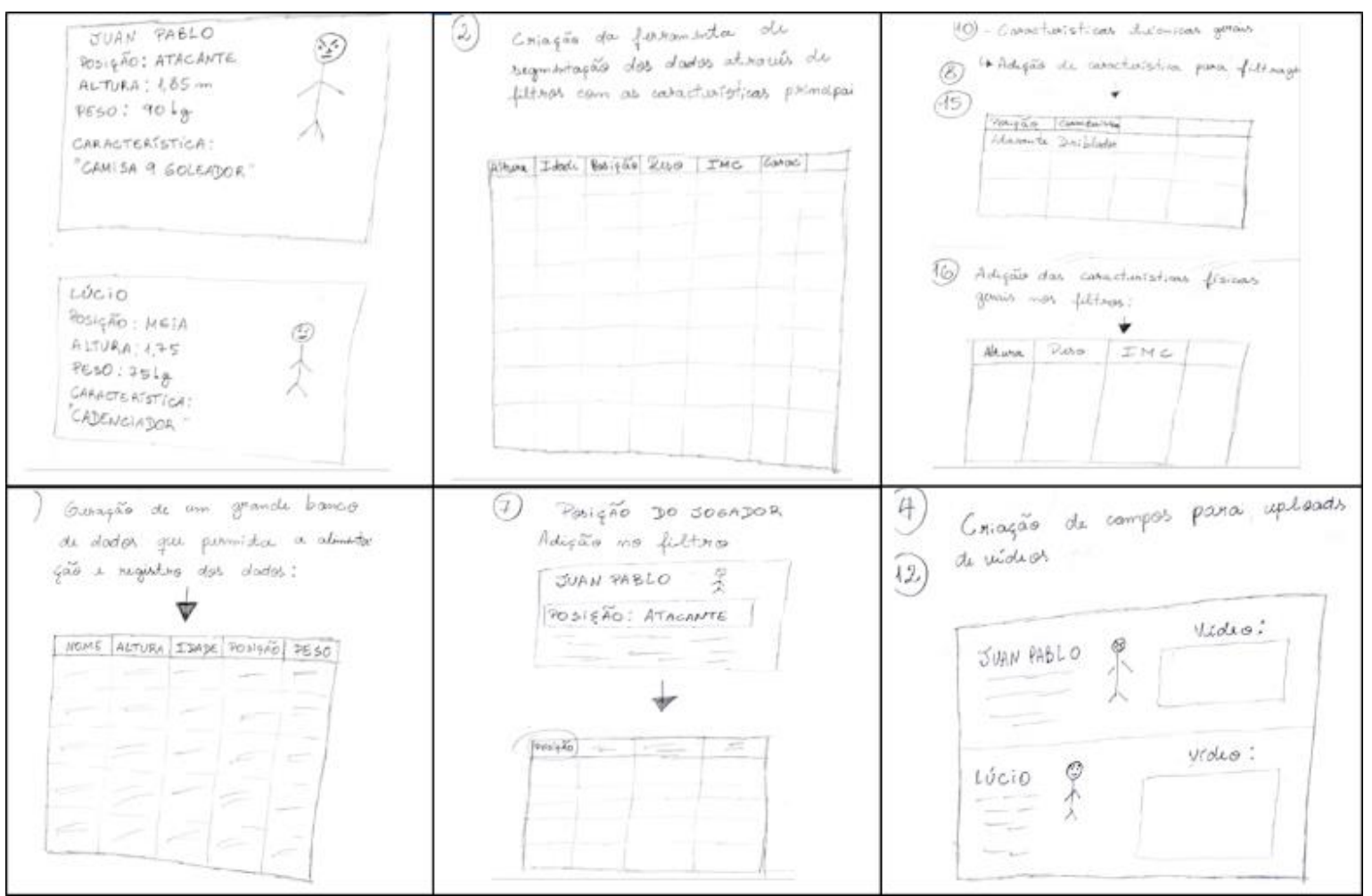

Figura 2 - Protótipos em papel dos componentes do produto final. Fonte: Elaborado pelo autor

Com este contexto em mente, a penúltima etapa do processo focou em fazer o protótipo final do produto e realizar a análise de riscos do aplicativo, pois assim conseguiu-se verificar como os requisitos foram colocados dentro do produto. Utilizando como base o catálogo de conceitos representado nos protótipos em folhas de papel, a prototipação do produto não funcional foi desenvolvida na plataforma de Design Marvel App.

É importante destacar que foram elaboradas todas as páginas do aplicativo, tanto para a visualização dos jogadores como também para a visualização dos clubes, englobando desde o logo, cadastro até as análises de dados. O protótipo final com as telas aparece na Figura 3. O protótipo pode ser acessado no link: Link JoinFut-Marvel App.

O protótipo criado permite ao usuário a geração de relatórios com as principais características dos atletas filtrados de acordo com as demandas dos analistas, como perna dominante, altura, peso e IMC englobando as características físicas, e posição, característica de jogo, representando as características técnicas. Além disso, a partir das necessidades dos mesmos, o aplicativo permite a criação de subgrupos de acompanhamento dos atletas préselecionados pelos clubes, para que estes profissionais consigam agrupar os dados conforme a seleção definida. Por exemplo, se o analista quiser um jogador da posição "Zagueiro" que tenha a característica "Canhoto", ele consegue agrupar os atletas dentro desta filtragem. 


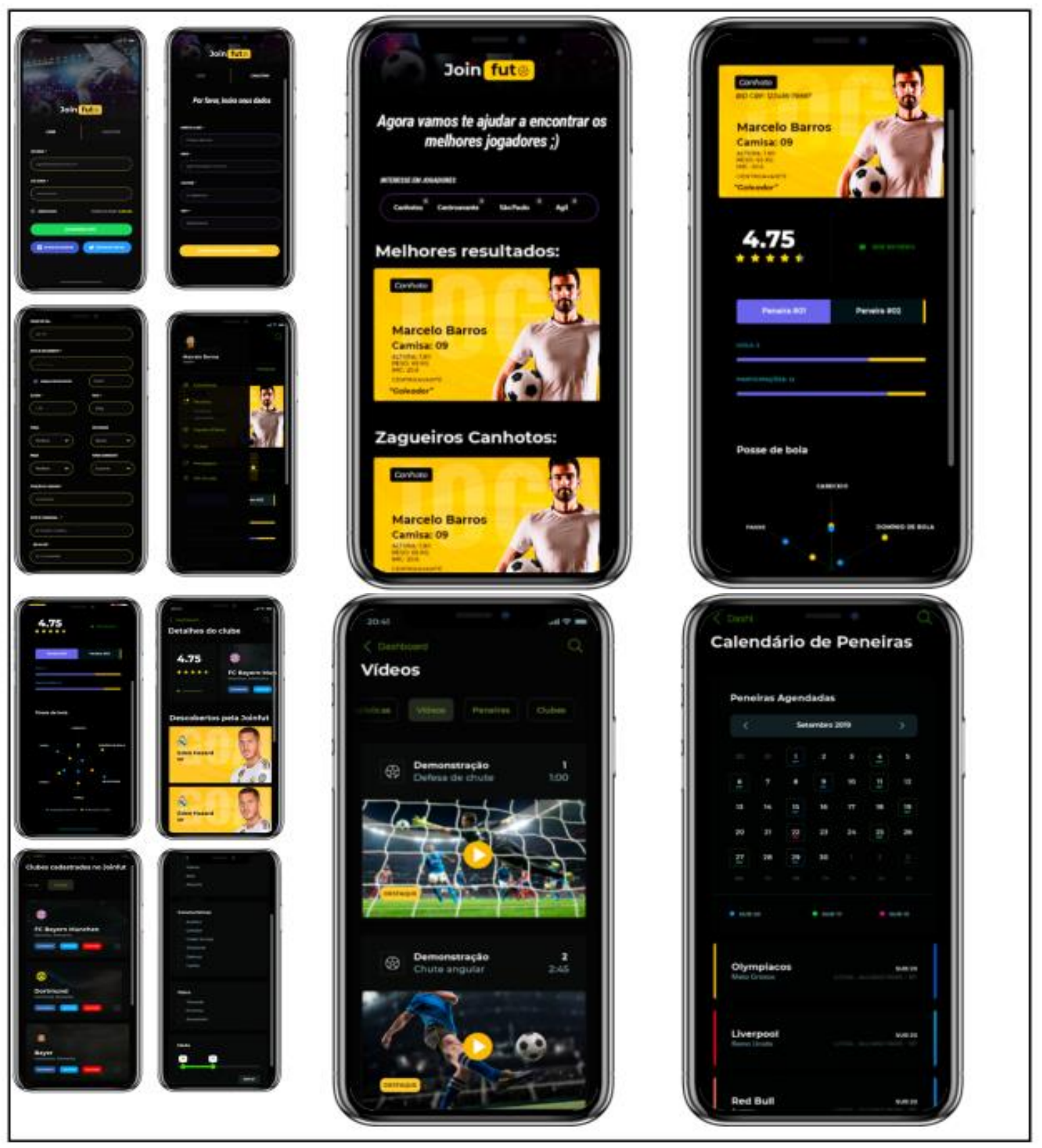

Figura 3 - Protótipo final. Fonte: Elaborado pelo autor

O relatório proporciona também a visualização dos vídeos dos atletas, a pontuação dos jogadores conforme a pré-avaliação realizada pelos analistas da empresa e também o número de registro do Boletim Informativo Diário (BID). Estas funcionalidades proporcionam aos analistas realizarem avaliações mais robustas de informações e de dados para a tomada de decisão. Os atletas têm a oportunidade de verificar o calendário de peneiras, para que se candidatem e se apliquem dentro das categorias avaliadas.

Para levantamento de riscos dos componentes foi feita a FMEA. Basicamente a análise concentrou-se em levantar os principais potenciais problemas de sistema que o aplicativo virá a ter. A Figura 4 apresenta a análise de riscos verificada para os componentes. 


\begin{tabular}{|c|c|c|c|c|c|c|c|c|c|c|}
\hline Requisito & Componente & Falha & Efeito & 苞 & Causa & : & Controles & ن⿺辶冋 & $\frac{0}{0}$ & Ação \\
\hline $\begin{array}{l}\text { Cronograma } \\
\text { de peneiras } \\
\text { embutido no } \\
\text { aplicativo. }\end{array}$ & $\begin{array}{l}\text { Ferramenta } \\
\text { informativa }\end{array}$ & $\begin{array}{l}\text { Erro na } \\
\text { informação } \\
\text { reportada ao } \\
\text { cliente }\end{array}$ & $\begin{array}{l}\text { Clientes não } \\
\text { terão a ciência } \\
\text { de quando as } \\
\text { peneiras } \\
\text { ocorrerão. }\end{array}$ & 4 & $\begin{array}{l}\text { Erro de digitação dos } \\
\text { dados; Falhas no } \\
\text { sistema }\end{array}$ & 7 & $\begin{array}{l}\text { Realizar } \\
\text { checagem das } \\
\text { informações } \\
\text { para verificação } \\
\text { da veracidade } \\
\text { dos dados }\end{array}$ & 9 & 252 & $\begin{array}{l}\text { Verificar datas e } \\
\text { clubes } \\
\text { informados }\end{array}$ \\
\hline $\begin{array}{l}\text { Segurança } \\
\text { das } \\
\text { informações }\end{array}$ & \begin{tabular}{|l|} 
Segurança \\
das \\
informações
\end{tabular} & \begin{tabular}{|l|} 
Dados \\
deletados, \\
invasão nos \\
dados, quebra \\
nos dados
\end{tabular} & \begin{tabular}{|l|} 
Problema \\
jurídicos \\
envolvidos, \\
Perda de dados - \\
Problemas \\
financeiros \\
recorridos
\end{tabular} & 9 & $\begin{array}{l}\text { Falha no planejamento } \\
\text { de segurança em cada } \\
\text { etapa de } \\
\text { desenvolvimento }\end{array}$ & 5 & $\begin{array}{l}\text { Estabelecer uma } \\
\text { preocupação } \\
\text { micro para cada } \\
\text { etapa da } \\
\text { execução do } \\
\text { processo }\end{array}$ & 5 & 225 & \begin{tabular}{|l|} 
Estabelecer \\
estrutura de \\
segurança das \\
informações \\
alinhada com os \\
principais \\
requerimentos \\
de mercado \\
\end{tabular} \\
\hline $\begin{array}{l}\text { Proporcionar } \\
\text { ao clube a } \\
\text { possibilidade } \\
\text { de geração de } \\
\text { relatórios. }\end{array}$ & $\begin{array}{l}\text { Relatórios } \\
\text { gerados }\end{array}$ & $\begin{array}{l}\text { Puxar } \\
\text { informações } \\
\text { incorretas, } \\
\text { devido a erro } \\
\text { do sistema. }\end{array}$ & $\begin{array}{l}\text { Inviabilização } \\
\text { do uso da } \\
\text { funcionalidade; } \\
\text { Exposição de } \\
\text { dados que não } \\
\text { agregam valor } \\
\text { ao processo de } \\
\text { seleção ( CPF, } \\
\text { teleffone) } \\
\end{array}$ & 10 & \begin{tabular}{|l|} 
Falha no \\
desenvolvimento, falha \\
no requisito, falha na \\
arquitetura do sistema \\
e/ou falha de teste
\end{tabular} & 5 & $\begin{array}{l}\text { Realizar testes } \\
\text { automáticos para } \\
\text { garantia da } \\
\text { ferramenta. } \\
\text { Estabelecer um } \\
\text { tempo grande de } \\
\text { desenvolvimento } \\
\text { para o produto. }\end{array}$ & 4 & 200 & $\begin{array}{l}\text { Realizar testes } \\
\text { automáticos para } \\
\text { garantia da } \\
\text { ferramenta. } \\
\text { Estabelecer um } \\
\text { tempo grande de } \\
\text { desenvolvimento } \\
\text { para o produto. }\end{array}$ \\
\hline $\begin{array}{l}\text { Pré-avaliação } \\
\text { embutida }\end{array}$ & \begin{tabular}{|l|} 
Ferramenta \\
de de plugin \\
de avaliação \\
para cada \\
jogador
\end{tabular} & $\begin{array}{l}\text { Puxar } \\
\text { avaliações } \\
\text { incorretas }\end{array}$ & $\begin{array}{l}\text { Não } \\
\text { conformidade } \\
\text { dos dados de } \\
\text { avaliação, } \\
\text { incorrendo em } \\
\text { um processo de } \\
\text { avaliação } \\
\text { quebrado } \\
\end{array}$ & 9 & \begin{tabular}{|l} 
Falha no \\
desenvolvimento, falha \\
na arquitetura do \\
sistema e/ou falha de \\
teste
\end{tabular} & 5 & \begin{tabular}{|l} 
Realizar testes \\
automáticos e \\
programáticos \\
para garantia do \\
funcionamento \\
pleno da \\
ferramenta.
\end{tabular} & 4 & 180 & \begin{tabular}{|l|} 
Planejar \\
testagem das \\
ferramentas; \\
Estabelecer e \\
programar um \\
grande tempo de \\
desenvolvimento \\
do produto. \\
\end{tabular} \\
\hline $\begin{array}{l}\text { Filtros de } \\
\text { características } \\
\text { técnicas e } \\
\text { físicas }\end{array}$ & $\begin{array}{l}\text { Filtros de } \\
\text { seleção }\end{array}$ & $\begin{array}{l}\text { Puxar } \\
\text { informações } \\
\text { incorretas, } \\
\text { devido a erro } \\
\text { de sistema. }\end{array}$ & $\begin{array}{l}\text { Inviabilização } \\
\text { do uso da } \\
\text { funcionalidade. }\end{array}$ & 10 & \begin{tabular}{|l|} 
Falha no \\
desenvolvimento, falha \\
no requisito, falha na \\
arquitetura do sistema \\
e/ou falha de teste
\end{tabular} & 5 & \begin{tabular}{|l} 
Controles e \\
gestão dos testes \\
automáticos para \\
garantia do \\
funcionamento \\
pleno da \\
ferramenta.
\end{tabular} & 3 & 150 & \begin{tabular}{|l|} 
Planejar \\
testagem das \\
ferramentas; \\
Estabelecer e \\
programar um \\
grande tempo de \\
desenvolvimento \\
do produto.
\end{tabular} \\
\hline $\begin{array}{l}\text { Registro de } \\
\text { vídeos }\end{array}$ & $\begin{array}{l}\text { Sistema de } \\
\text { Upload de } \\
\text { vídeos }\end{array}$ & \begin{tabular}{|l|} 
Problemas de \\
rodagem c/ \\
formato do \\
vídeo. \\
'Problemas c/ \\
integração do \\
sistema do \\
terceiro \\
\end{tabular} & $\begin{array}{l}\text { Inviabilização } \\
\text { da visualização } \\
\text { do vídeo }\end{array}$ & 10 & $\begin{array}{l}\text { Formato do vídeo e } \\
\text { falha de integração } \\
\text { com do servidor do } \\
\text { terceiro com a } \\
\text { aplicação }\end{array}$ & 5 & $\begin{array}{l}\text { - Contratar um } \\
\text { servidor potente } \\
\text { para a rodagem } \\
\text { dos vídeos } \\
\text { '- Restringir o } \\
\text { formato dos } \\
\text { vídeos em mp3 } \\
\text { ou mp4 }\end{array}$ & 3 & 150 & \begin{tabular}{|l|} 
Contratar um \\
servidor potente \\
para a rodagem \\
dos vídeos \\
Restringir o \\
formato dos \\
vídeos em mp3 \\
ou mp4 \\
\end{tabular} \\
\hline $\begin{array}{l}\text { Utilização do } \\
\text { Big Data. }\end{array}$ & $\begin{array}{l}\text { Grande } \\
\text { banco de } \\
\text { dados }\end{array}$ & $\begin{array}{l}\text { Segurança: } \\
\text { Vazamento } \\
\text { dos dados }\end{array}$ & \begin{tabular}{|l|} 
Problema \\
jurídicos \\
envolvidos, \\
Perda de dados - \\
Problemas \\
financeiros \\
recorridos \\
\end{tabular} & 10 & $\begin{array}{l}\text { Falha de arquitetura, } \\
\text { falha de segurança, } \\
\text { falha de } \\
\text { desenvolvimento. }\end{array}$ & 5 & $\begin{array}{l}\text { Estabelecer um } \\
\text { padrão de } \\
\text { segurança no } \\
\text { serviço. }\end{array}$ & 3 & 150 & \begin{tabular}{|l|} 
Equipe de \\
desenvolvimento \\
necessita \\
estabelecer um \\
padrão de \\
segurança no \\
serviço. \\
\end{tabular} \\
\hline $\begin{array}{l}\text { Criação de } \\
\text { subgrupos }\end{array}$ & \begin{tabular}{|l|} 
Sistema \\
interno que \\
permite o \\
agrupamento \\
de \\
informações
\end{tabular} & \begin{tabular}{|l|} 
Puxar \\
informações \\
incorretas no \\
agrupamento, \\
devido a erros \\
de sistema.
\end{tabular} & $\begin{array}{l}\text { Inviabilização } \\
\text { do uso da } \\
\text { funcionalidade. }\end{array}$ & 10 & \begin{tabular}{|l|} 
Falha no \\
desenvolvimento, falha \\
no requisito, falha na \\
arquitetura do sistema \\
e/ou falha de teste
\end{tabular} & 5 & \begin{tabular}{|l} 
Realizar testes \\
automáticos e \\
programáticos \\
para garantia do \\
funcionamento \\
pleno da \\
ferramenta.
\end{tabular} & 3 & 150 & \begin{tabular}{|l|} 
Planejar \\
testagem das \\
ferramentas; \\
Estabelecer e \\
programar um \\
grande tempo de \\
desenvolvimento \\
do produto. \\
\end{tabular} \\
\hline $\begin{array}{l}\text { Interligação } \\
\text { com bases de } \\
\text { dados de } \\
\text { federações. }\end{array}$ & $\begin{array}{l}\text { Ferramenta } \\
\text { de conexão } \\
\text { dos dados } \\
\text { com os } \\
\text { bancos de } \\
\text { dados de } \\
\text { federações } \\
\text { esportivas } \\
\end{array}$ & \begin{tabular}{|l|} 
Comunicação \\
entre os \\
bancos de \\
dados; \\
Problemas de \\
segurança \\
com o sistema \\
terceiro.
\end{tabular} & $\begin{array}{l}\text { Funcionalidade } \\
\text { falha e } \\
\text { desconexa/ } \\
\text { Inacessível }\end{array}$ & 6 & $\begin{array}{l}\text { Atualizações/mudanças } \\
\text { do sistema terceiro; }\end{array}$ & 8 & $\begin{array}{l}\text { Não há controle } \\
\text { sobre este } \\
\text { processo }\end{array}$ & 1 & 48 & \begin{tabular}{|l|} 
Entrar em \\
contato com a \\
empresa; ter um \\
sistema de \\
monitoramento \\
contínuo entre \\
os dois negócios
\end{tabular} \\
\hline
\end{tabular}

Figura 4 - FMEA do produto. Fonte: Elaborado pelo autor 
Percebe-se que as potenciais falhas de maior pontuação de risco se referem a "Ferramenta informativa com os principais dados dos jogadores" e "segurança das informações". A primeira trata dos erros dos dados que são reportados aos clientes, que podem ser causados por erros de digitação dos usuários e também com as falhas de sistema. Com pontuação de 252, para mitigá-lo foi colocada a ação de inspeção e checagem dos dados, que será delegada à equipe de desenvolvimento de produto e manutenção.

A segunda conta sobre o risco de o produto ter que ou invasão de dados, problema frequente em aplicativos com grande carga de informações. Para mitigar o risco, estabeleceuse como controle o planejamento de segurança para cada etapa do aplicativo, desde o cadastro até a análise dos profissionais dos clubes. Como ação para isso, empresa indica contratar programadores especializados em segurança de dados.

Destaca-se também o item de menor pontuação do FMEA, caracterizado pela ferramenta de vinculação do BID da CBF com os atletas cadastrados, componente de extrema importância para o cliente. Relata a comunicação entre os dois bancos de dados envolvidos, onde problemas com a segurança dos dados do sistema terceiro não está gerido e controlado pela JoinFut. Se torna uma falha fácil de ser identificada, fato este que torna o valor final de risco baixo. Para mitigá-la, foi proposta a ação de criar um sistema de monitoramento contínuo entre as duas empresas, CBF e JoinFut, estabelecendo contato constante de informações entre os departamentos de desenvolvimento e manutenção do produto.

\subsection{Teste}

A partir dos resultados da pesquisa com os usuários, foi possível resgatar o feedback quantitativo e qualitativo dos usuários. Com isso, conseguiu-se analisar os aspectos com melhor avaliação e quais devem melhorar, considerando que o protótipo foi feito em uma primeira rodada de análise. Na verificação dos resultados, foi percebido que a pesquisa foi respondida por dois analistas de futebol e seis ex-jogadores de futebol, ou seja, todos com grande experiência no ambiente esportivo.

A pesquisa realizada compreendeu os requisitos levantados. Para a mensuração, assim como na pesquisa de mercado, parametrizou-se de 1 a 5 o grau de satisfação dos usuários com os resultados. Assim, o 1 representa grau de satisfação muito baixo e 5, grau de satisfação alta. A Tabela 1 apresenta a média aritmética dos resultados conforme o grau de satisfação.

Percebe-se que, de uma forma geral, o protótipo teve boa aceitação dos usuários, que colocaram informações importantes para a melhoria do produto. Os requisitos que tiveram pior resultado na avaliação - que se referem à forma como foram distribuídas as características 
físicas dos jogadores e à pré-avaliação embutida dos analistas - foram colocados no protótipo, pois sabia-se que são extremamente importantes para os clientes.

Tabela 1 - Resultados da aplicação do teste de usabilidade do protótipo final.

\begin{tabular}{|c|c|c|}
\hline Requisito & Pergunta relativa ao requisito (Qual seu grau de satisfação ...) & $\begin{array}{c}\text { Média } \\
\text { Aritmética } \\
\text { (escala 1 a 5) }\end{array}$ \\
\hline 1 & ... da forma como foram apresentadas as características físicas dos atletas? & 4,62 \\
\hline 2 & ... sobre a forma como as características técnicas foram mostradas? & 4,87 \\
\hline 3 & $\begin{array}{l}\text {... sobre a forma como foram apresentadas a pré-avaliação realizada pela JoinFut e pelos } \\
\text { clubes sobre os desempenhos dos jogadores ? }\end{array}$ & 4,62 \\
\hline 4 & ... sobre a forma como foi mostrado o cronograma de peneiras ? & 4,75 \\
\hline 5 & ... sobre a forma como foi disposto o código do BID e seu vínculo com o jogador ? & 4,87 \\
\hline 6 & $\begin{array}{l}\text {... sobre a forma como foram apresentados os filtros aplicados para a verificação dos } \\
\text { atletas? }\end{array}$ & 4,75 \\
\hline 7 & ... sobre a forma como foram apresentados os vídeos dos atletas? & 4,87 \\
\hline 8 & ... sobre a forma como os filtros foram apresentados? & 4,75 \\
\hline 9 & ... sobre a forma como foram dispostos os relatórios no aplicativo ? & 4,87 \\
\hline \multirow[t]{2}{*}{10} & ... com a maneira de que foram apresentados os subgrupos no aplicativo? & 4,75 \\
\hline & Média geral & $4,7=95 \%$ \\
\hline
\end{tabular}

Fonte: Elaborado pelo autor

Sobre o primeiro item citado, os clientes colocaram que as características físicas não são 100\% confiáveis, e este fato limita o alcance da seleção e captação dos atletas, além de estar faltando a data de nascimento dos atletas. Com relação ao segundo ponto, foi colocado que a análise prévia é importante para os responsáveis pela captação, apesar de ser subjetiva em um primeiro momento, a partir da primeira avaliação.

Outra colocação importante levantada na pesquisa relaciona-se aos filtros. Surgiu a necessidade para os usuários a filtragem da origem dos atletas, apresentando no aplicativo o estado onde o jogador mora, para que os clubes possam fazer a segmentação por estado.

\section{CONCLUSÃO}

Considerando a necessidade atual dos clubes e atletas têm em utilizar um software facilitador do processo de captação e seleção de atletas, o trabalho realizado tinha como objetivo prototipar e testar um aplicativo que entregue este serviço. A proposta foi alcançada, visto se gerou um protótipo que atende os principais requisitos da qualidade e melhorias potenciais do produto pela mitigação de riscos. Com relação aos objetivos específicos definidos, compreendese que também foram alcançados, considerando que o designer prototipou, testou e validou a solução com os stakeholders. Além disso, foram levantadas melhorias sugeridas pelos mesmos.

Foi percebido que que o método pode ser aplicado para vários estudos que visam estudar e propor soluções a novos entrantes no mercado e também para desenvolver inovação dentro dos produtos e serviços já existentes. Por causa da baixa possibilidade de alto investimento, não foi possível realizar um software real, limitando-se apenas ao protótipo virtual. Com isso, para 
futuros trabalhos é sugerida a realização do protótipo real do aplicativo com as melhorias levantadas na etapa de teste. Em decorrência disto, uma segunda rodada de desenvolvimento poderia ser feita para aprimorar o desempenho do software em ambiente real.

\section{REFERENCIAS}

BROWN, T.; KATZ, B. Change by design: how Design Thinking transforms organizations and inspires inovation. New York, NY: HarperBusiness, 2019.

CBF - CONFEDERAÇÃO BRASILEIRA DE FUTEBOL; EY - ERNST \& YOUNG. Impacto do Futebol no Mercado Brasileiro. 2019. Disponível em:

https://conteudo.cbf.com.br/cdn/201912/20191213172843 346.pdf Acessado em: 12 de out de 2021.

ERTHAL, J. M.; LEMOS, R. Sonho de muitos, chance para poucos. Veja, São Paulo, 2010.

Disponível em: https://veja.abril.com.br/esporte/sonho-de-muitos-chance-para-muito-poucos/ . Acesso em: 12 de outubro de 2021.

ESTANISLAU, A. Comparação de diferentes sistemas de análise de desempenho no futebol: Proposta na utilização do software. Trabalho de Conclusão de Curso (Bacharel em Ciências do Esporte) - Faculdade de Ciências Aplicadas, Universidade Estadual de Campinas, Limeira, 2016.

HPID - HASSO PLATTNER Design Thinking Bootleg - Institute Of Design Thinking At Stanford University. 2018.

LOPES, L.A. Como se tornar um jogador de futebol ? Revista Super Interessante. São Paulo, 2018. Disponível em: https://super.abril.com.br/mundo-estranho/como-se-tornar-um-jogador-de-futebol/ . Acesso em: 12 de outubro de 2021.

MOURA, H.V. A Evolução do Futebol através da Ciência e da Tecnologia. Universidade de Taubaté, 1997.

NIELSEN COMPANY, Nielsen's World Football Report. 2018.

ROSA, S. E. M. Aspirante a craque de futebol hoje ou marginal do amanhã? ?. Revista JUS Navegandi, Teresina, ano 14, n.2122, abr. 2009. Disponível em: https://jus.com.br/artigos/12681 . Acesso em: 12 de outubro de 2021.

ROSSI, V. C.A.; SLONGO, A. L. Pesquisa de satisfação de clientes: o estado-da-arte e proposição de um método brasileiro. Revista de Administração Contemporânea. v.2, n.1. Curitiba. 1998.

RUSSO, C.R. Marketing Esportivo. 2008. Monografia (Graduação) - Faculdade de Tecnologia e Ciências Aplicadas, Centro Universitário de Brasília, Brasília, 2008.

SILBERMANN, M. Jogador-Informação: uma etnografia dos usos de tecnologias informacionais no incremento do desempenho de jogadores de futebol. Monografia (Graduação) - Instituto de Filosofia e Ciências Humanas, Universidade Federal do Rio Grande do Sul, Porto Alegre, 2010.

SILVA, M. A.; CORREA, C. S.A.; SILVA FILHO, M.R.J.; SOUZA, A.C. R. Aplicação do Design Thinking em um problema educacional: um relato de experiência. In: CONGRESSO BRASILEIRO DE INFORMÁTICA NA EDUCAÇÃO, 5./Workshop de Informática na Escola, 22., 2016, Uberlândia. Anais .... Porto Alegre: SBC, 2016. p.904-913. 